\title{
Biologically active extracellular products of oral viridans streptococci and the aetiology of Kawasaki disease
}

\author{
H. OHKUNI, YUKO TODOME, M. MIZUSE, N. OHTANI, H. SUZUKI, H. IGARASHI*, \\ Y. HASHIMOTO†, T. EZAKI†, K. HARADA
}

Division of Immunology, Institute of Gerontology, Nippon Medical School, 1-396, Kosugi-cho, Nakahara-ku, Kawasaki, Kanagawa 211, "Department of Microbiology, Tokyo Metropolitan Research Laboratory of Public Health, Sinjyuku-ku, Tokyo 160, †Department of Microbiology, School of Medicine, Gifu University, Gifu 500,

$\ddagger$ Department of Microbiology, Osaka Prefectural Institute for Public Health, Higashi-ku, Osaka 537, §Department of Pediatrics, Japan Red Cross Medical Centre, Shibuya-ku, Tokyo 150 and || Osaka College of Medical Technology, Kita-ku, Osaka 530, Japan

\begin{abstract}
Summary. A bacteriological study of isolates from the oral cavity of patients with Kawasaki disease (KD), age-matched non-KD patients and healthy children, showed that over half the $\mathrm{KD}$ and control isolates had gram-positive, catalase-negative cocci. About $50 \%$ of these organisms were identified as viridans streptococci by means of an API Strep 20 kit. Further identification by fluorometric DNA-DNA hybridisation demonstrated that the predominant species were S. oralis and S. mitis, each of which accounted for $25 \%$ of the isolates of viridans streptococci; $40 \%$ of viridans strains were unidentifiable; and S. sanguis and $S$. parasanguis were minor components. Studies in vivo showed that insertion of culture supernates of most of the viridans streptococci increased capillary permeability and induced redness with swelling and occasional bleeding in rabbit skin. One-third of S. mitis strains and one-fifth of the unidentified strains caused aggregation of human blood platelets, whereas $S$. oralis and other strains had no such effect. The distribution of extracellular lipoteichoic acids and glucan produced in the presence of sucrose was also examined. There were no significant differences in the recovery rate of viridans streptococci forming these biologically active extracellular products between $\mathrm{KD}$ and control groups.
\end{abstract}

\section{Introduction}

The epidemiological features, clinical symptoms and laboratory findings of Kawasaki disease (KD)-acute febrile, mucocutaneous, lymph node syndrome-have suggested that a possible cause is an infectious organism $^{1}$ resident in the oral cavity or throat whose toxic and biologically active products are capable of causing immunological disorders and inflammatory reactions. ${ }^{2-4}$

However, several attempts to identify a specific microbe that would satisfy Koch's postulates, particularly one recoverable exclusively from $\mathrm{KD}$ patients, have so far failed. So we speculated that the causative agent of $\mathrm{KD}$ is either an organism that cannot be isolated by conventional techniques or an agent that requires other factors to produce clinical symptoms and signs as well as pathological changes.

As the first step in a study based on the hypothesis that oral or throat bacteria capable of producing biologically active factors are involved in the pathogenesis of $\mathrm{KD}$, we attempted to isolate a significant group of bacteria from KD patients and age-matched control children that could produce immunobiologically active extracellular factors.

\section{Materials and methods}

\section{Patients}

KD patients were diagnosed according to the clinical criteria proposed by the study group on KD, the Ministry of Welfare, Japan, ${ }^{5}$ at the Japan Red Cross Medical Centre (Tokyo), 1983, 1990 and 1991, the National Cardiovascular Centre (Osaka) and the Second Hospital, Nippon Medical School (Kawasaki), 1990 and 1991 . The age of the KD patients ranged from 3 months to 6 years. Age-matched controls (23) were either patients with non-KD febrile diseases (17) including pharyngitis, viral pneumonia, viral meningitis, exanthema subitum, salmonella enteritis and acute bronchitis, or healthy children (6).

\section{Collection of specimens}

Clinical specimens were collected with sterile swabs 
taken from the throat and tooth surfaces of 89 patients with KD during the acute phases, 2-5 days after onset, and before intravenous gammaglobulin therapy, from 17 children with other febrile diseases and from six healthy children.

\section{Isolation procedures and classification of clinical isolates}

Swabs were transported promptly from the clinic to the laboratory in $\mathrm{CO}_{2}$-enriched anaerobic transport medium (Kenki Porter, Clinical Supply, Gifu, Japan). Microbes on the swabs were transferred to GAM semi-solid medium (Gifu Anaerobic Medium, Nissui Corp., Tokyo, Japan) and cultured at $37^{\circ} \mathrm{C}$ for 24-48 h. Bacteria were streaked on pairs of Columbia Sheep Blood Agar plates (bioMérieux, Marcy L'Etoile, France). One of each pair was cultured aerobically and the others were incubated anaerobically in jars made anaerobic with the Gas Pak system (Becton Dickinson Microbiology System, Cockeysville, MD, USA) at $37^{\circ} \mathrm{C}$ for $24 \mathrm{~h}$. Representative single colonies on the blood-agar plates in Gas Pak jars were selected, streaked again on blood agar plates and cultured aerobically at $37^{\circ} \mathrm{C}$ for $24 \mathrm{~h}$. The fact that virtually $100 \%$ recovery was achieved by this method indicated that all bacteria grown in the Gas Pak can grow aerobically. The strains obtained in pure culture were inoculated in GDO (Groups of Difficult Organisms) medium (Nissui Corp.) devised to store groups of "difficult organisms" and stored at $-20^{\circ} \mathrm{C}$ until use.

The isolates were cultured aerobically on bloodagar plates at $37^{\circ} \mathrm{C}$ for $18 \mathrm{~h}$, and the bacteria that had grown were stained by Gram's method. Gram-positive cocci were then checked by the catalase test, ${ }^{6}$ and divided into catalase-positive and -negative groups. Gram-negative rods were divided into oxidase-positive and -negative groups. Bacterial strains isolated from KD patients and control children were thus broadly divided into the following genera and groups. (1) Micrococcus and Staphylococcus (gram-positive, catalase-positive cocci); (2) Streptococcus, Enterococcus and Lactococcus (gram-positive, catalase-negative cocci); (3) Bacillus and Corynebacterium (grampositive bacilli); (4) Neisseriaceae (gram-negative cocci); (5) Non-fermenting gram-negative bacteria (gram-negative, oxidase-positive bacilli); (6) Enterobacteriaceae (gram-negative, oxidase-negative bacilli).

We concentrated on group 2 described above, which accounted for more than half of all isolates from both KD and control children (table I): 98 and 27 strains derived from clinical specimens from 22 patients with $\mathrm{KD}$ and 11 with other febrile diseases, respectively, collected at the Department of Pediatrics, Japan Red Cross Medical Center (Tokyo) in 1990-1991 were identified according to the manufacturer's manual for the API Strep 20 kit (bioMérieux, LaBalme les Grottes, France) and the Analytical Profile Index.

\section{Identification of viridans group streptococci by fluorometric DNA-DNA hybridisation}

Gram-positive, catalase-negative $\alpha$-haemolytic cocci classified into three groups, $S$. sanguis II, $S$. sanguis II or $S$. pneumoniae and $S$. mitis (see table II) were identified by fluorometric hybridisation in microdilution wells. ${ }^{7-9}$ Reference strains $S$. mitis ATCC903, ATCC6249 and ATCC15911, S. oralis ATCC9811 and $S$. parasanguis ATCC15909 were also identified by this method. The type strains were as follows: $S$. dysgalactiae NCFB2023, S. suis NCTC10234, S. pneumoniae NCTC7465, $S$. oralis NCTC11427, $S$. mitis NCTC12261 (neotype), S. sanguis ATCC10556, S. parasanguis ATCC15912, S. gordonii NCTC7865, $S$. salivarius ATCC7073, S. intermedius ATCC27335 and Escherichia coli $\mathrm{K}-12$. A $100-\mu \mathrm{l}$ volume of heatdenatured reference DNA $(10 \mu \mathrm{g} / \mathrm{ml})$ in phosphatebuffered saline (PBS), pH 7.2, containing $0 \cdot 1 \mathrm{M} \mathrm{MgCl}_{2}$ was incubated for $1 \mathrm{~h}$ at $37^{\circ} \mathrm{C}$ in a microdilution well (MicroFluor "B" plate, Dynatech Laboratories Inc., Alexandria, VA, USA). The solution was removed and the plate was dried at $45^{\circ} \mathrm{C}$ for several hours to immobilise the DNA. A $200-\mu 1$ volume of pre-hybridisation solution containing $200 \mu \mathrm{g}$ of denatured salmon sperm DNA (Sigma) was added to each well and incubated at $45^{\circ} \mathrm{C}$ for $1 \mathrm{~h}$. The pre-hybridisation solution was discarded and replaced with $100 \mu \mathrm{l}$ of hybridisation solution containing 10-20 ng of biotinylated DNA of clinical isolates/well. Hybridisation proceeded for $2 \mathrm{~h}$ at $45^{\circ} \mathrm{C}$. The wells were washed three times with PBS containing Triton X100 0.1\% (PBS$\mathrm{T})$. One hundred $\mu \mathrm{l}$ of $0.3 \mathrm{U} / \mathrm{ml}$ of streptavidinconjugated $\beta$-D-galactosidase (Zymed Laboratories Inc., San Francisco, CA, USA) dissolved in PBS-T containing bovine serum albumin 2\% (PBS-BSA-T) were added to the wells and incubated at $37^{\circ} \mathrm{C}$ for $15 \mathrm{~min}$. The plate was washed with PBS-T and a $50 \mu \mathrm{l}$ volume of $3 \times 10^{-4} \mathrm{M}$ methylumbelliferyl- $\beta$-D-galactopyranoside (Koch-light Ltd, Haverhill, Suffolk) in PBS-BSA was added to each plate. After incubation at $30^{\circ} \mathrm{C}$ for $30 \mathrm{~min}$, the intensity of developing fluorescence was measured with a Micro Fluor reader (Dynatech Laboratories Inc.) at a wavelength of $360 \mathrm{~nm}$ for excitation and at $450 \mathrm{~nm}$ for emission. The intensity of fluorescence in the well containing salmon sperm DNA was taken at zero, and in the well that emitted the strongest fluorescence this was taken as $100 \%$. E. coli DNA served as a negative control. When the second highest intensity was $<70 \%$ and the ratio of the maximum: control value $>5$, a test strain was identified as being of the same species as the type strain that gave the greatest intensity.

\section{Preparation of culture supernate concentrate}

Test strains of viridans streptococci were cultured in $5 \mathrm{ml}$ of a chemically defined medium $(\mathrm{CDM}){ }^{10}$ at $37^{\circ} \mathrm{C}$ for $18 \mathrm{~h}$ in a $\mathrm{CO}_{2} 5 \%$ incubator. Each growth was transferred to a flask containing $500 \mathrm{ml}$ of CDM and 
Table I. Identification of bacterial isolates from $89 \mathrm{KD}$ patients and 23 control children consisting of 17 non-KD patients and 6 healthy children

\begin{tabular}{|c|c|c|}
\hline \multirow{2}{*}{ Identification } & \multicolumn{2}{|c|}{ Percentage of total isolates } \\
\hline & $\underset{(256)^{*}}{\mathrm{KD}}$ & $\begin{array}{l}\text { control } \\
(85)\end{array}$ \\
\hline $\begin{array}{l}\text { Micrococcus spp. } \\
\text { Staphylococcus spp. }\end{array}$ & $17 \cdot 3$ & $20 \cdot 4$ \\
\hline $\begin{array}{l}\text { Streptococcus spp. } \\
\text { Enterococcus spp. } \\
\text { Lactococcus spp. }\end{array}$ & $60 \cdot 9$ & $55 \cdot 1$ \\
\hline $\begin{array}{l}\text { Bacillus spp. } \\
\text { Corynebacterium spp. }\end{array}$ & $6 \cdot 2$ & $8 \cdot 2$ \\
\hline $\begin{array}{l}\text { Neisseriaceae } \\
\text { Non-fermenting gram- } \\
\text { negative bacteria }\end{array}$ & $\begin{array}{c}0 \\
14.9\end{array}$ & $\begin{array}{c}0 \\
10 \cdot 2\end{array}$ \\
\hline Enterobacteriaceae & $0 \cdot 6$ & $6 \cdot 1$ \\
\hline
\end{tabular}

* Number of isolates.

Table II. Identification of gram-positive, catalase-negative cocci isolated from $22 \mathrm{KD}$ patients and from 11 control children with an API Strep 20 kit

\begin{tabular}{|c|c|c|}
\hline \multirow{2}{*}{$\begin{array}{l}\text { Identification with } \\
\text { API Strep } 20 \\
\text { (code no.) }\end{array}$} & \multicolumn{2}{|c|}{$\begin{array}{l}\text { Number (\%) of } \\
\text { isolates from }\end{array}$} \\
\hline & KD & control \\
\hline \multicolumn{3}{|l|}{ S. sanguis II } \\
\hline$(0240040)$ & 1 & 0 \\
\hline$(0260440)$ & 0 & 1 \\
\hline$(0260441)$ & 7 & 4 \\
\hline (0261440) & 1 & 0 \\
\hline$(0262441)$ & 1 & 0 \\
\hline (0270441) & 2 & 0 \\
\hline$(0270451)$ & 0 & 1 \\
\hline \multicolumn{3}{|l|}{ S. sanguis II or } \\
\hline$(0240440)$ & 1 & 0 \\
\hline (0240441) & 2 & 0 \\
\hline$(0240450)$ & 2 & 1 \\
\hline (0250441) & 1 & 2 \\
\hline Subtotal & $18(18 \cdot 4)$ & $9(33 \cdot 3)$ \\
\hline \multicolumn{3}{|l|}{ S. mitis } \\
\hline$(0040400)$ & 8 & 1 \\
\hline$(0040401)$ & 5 & 1 \\
\hline (0042403) & 1 & 0 \\
\hline$(0050400)$ & 3 & 0 \\
\hline$(0050401)$ & 5 & 0 \\
\hline (0050461) & 0 & 1 \\
\hline$(0051400)$ & 1 & 0 \\
\hline$(0060400)$ & 1 & 0 \\
\hline$(0060401)$ & 3 & 4 \\
\hline$(0070400)$ & 1 & 0 \\
\hline$(0070401)$ & 5 & 0 \\
\hline$(0070420)$ & 1 & 0 \\
\hline Subtotal & $34(34 \cdot 7)$ & $7(25 \cdot 9)$ \\
\hline Others* & $46(46 \cdot 9)$ & $11(40 \cdot 9)$ \\
\hline Total & $98(100)$ & $27(100)$ \\
\hline
\end{tabular}

* S. sanguis I, S. salivarius, $S$. bovis, $S$. canis, S. equisimilis, $S$. pneumoniae 1 or 2, E. faecalis, E. faecium, E. avium, L. cremoris, $L$. lactis, A. viridans, G. morbillorum etc.

incubated at $37^{\circ} \mathrm{C}$ for $18 \mathrm{~h}$. The culture supernate obtained by centrifugation at $10000 \mathrm{~g}$ for $30 \mathrm{~min}$ at $4^{\circ} \mathrm{C}$ was filtered through a $0.45 \mu \mathrm{m}$ membrane filter
(Millipore Co., Bedford, MA., USA), placed in dialysis tubing with mol. mass cut-off of 12000-14000 (Sanko Pure Chemical Co., Tokyo), and concentrated by dialysis against Aquacide II, a sodium salt of carboxymethyl cellulose of high viscosity, mol. wt 500000 (Calbiochem Corp., LaJolla, CA, USA). The dialysis tube contents were washed out with $5 \mathrm{ml}$ of $0.15 \mathrm{M}$ PBS, $\mathrm{pH} 7 \cdot 2$, and adjusted to $\mathrm{pH} 7.2$ with $\mathrm{NaHCO}_{3} \quad 0 \cdot 1 \%$ if necessary. The culture supernate concentrated about 100 -fold was sterilised by filtration through a $0 \cdot 45-\mu \mathrm{m}$ membrane filter and the protein content was measured by the Lowry method. ${ }^{11}$ The culture supernate concentrate thus obtained was used in experiments as the test extracellular products.

\section{Vascular permeability and erythrogenic effects on rabbit skin}

Into the depilated dorsal skin of albino, female domestic rabbits weighing c. $2.5 \mathrm{~kg}$ (Nippon Biosupply Centre, Tokyo) $0 \cdot 1 \mathrm{ml}$ of test specimens, containing protein $0.8-1.0 \mathrm{mg} / \mathrm{ml}$ in $0.15 \mathrm{M}$ PBS, was injected intradermally at intervals. Skins were then examined for redness, swelling and bleeding. After the final intradermal injection, the rabbits were given an intravenous injection of aqueous Evans blue $1 \cdot 0 \%$. After $30 \mathrm{~min}$, the rabbits were killed, the skin was dissected from the abdominal wall and turned inside out to look for any blue colour due to dye leakage (an indication of increased capillary permeability), and bleeding of the test skin sites. ${ }^{12}$ A piece of skin was fixed with formalin, embedded in paraffin and stained with haematoxylin and eosin ( $\mathrm{H}$ and $\mathrm{E}$ ) by conventional procedures. The intensity of blue dye and redness with swelling, with or without bleeding was scored macroscopically as,-+ or ++ .

\section{Blood platelet aggregation}

Human peripheral blood was obtained from only one adult female donor (YT) throughout the study. Nine volumes (either 4.5 or $9.0 \mathrm{ml}$ ) of peripheral blood were drawn into a syringe containing one volume $(0.5$ or $1.0 \mathrm{ml}$ ) sodium citrate $3.8 \%$. Platelet-rich plasma (PRP) was obtained by centrifugation of the citrated blood at $170 \mathrm{~g}$ for $10 \mathrm{~min}$ at $20^{\circ} \mathrm{C}$. Aggregation of a mixture consisting of $200 \mu \mathrm{l}$ of PRP and $20 \mu \mathrm{l}$ of a test or a reference specimen was determined at $37^{\circ} \mathrm{C}$ with a two-channel aggregometer (Model PAT-2A, Nikko Bioscience Ltd, Tokyo) attached to a tracer (Model T228, Nikko Bioscience Ltd). Adenosine 5'-diphosphate (ADP, Sigma) in saline $0.85 \%\left(10^{-3} \mathrm{M}\right)$ served as the reference aggregation agent. The aggregation activity was measured $7 \mathrm{~min}$ after the addition of a test or reference specimen to the PRP. The potency of ADP in terms of increased light transmission of the reaction mixture was taken as $100 \%$, and that of each test specimen was expressed as a percentage of that of ADP. Values $>10<50 \%$ were scored + , and those $>50 \%$, ++ ; values $<10 \%$ were discarded. 


\section{Haemolytic activity}

A mixture of $50-\mu \mathrm{l}$ volumes of a test specimen and a sheep red blood cell (SRBC) $2 \%$ suspension in $0.01 \mathrm{M}$ PBS, pH 7.2, was examined for haemolysis on a microtitration plate (Nunc, Roskilde, Denmark) after incubation overnight at room temperature. Complete and partial haemolysis were scored as ++ and + , respectively. Marginal haemolysis was designated \pm .

\section{Detection of lipoteichoic acids}

An antiserum to lipoteichoic acid (LTA) was prepared by immunising albino female rabbits (Nippon Biosupply Centre) weighing $c .3 \cdot 0 \mathrm{~kg}$ with lyophilised Enterococcus hirae (E. faecalis, ATCC9790) whole cells (a gift from Dr K. Kato, School of Dentistry, Okayama University, Okayama, Japan). This was done as follows. Rabbits received foot-pad injections four times at 10-day intervals with $10 \mathrm{mg}$ of whole cells, of $E$. hirae suspended in $0.01 \mathrm{M}$ PBS, pH 7.2, and emulsified in Freund's complete adjuvant (Difco). An anti-LTA serum was obtained 10 days after the fourth injection, and semi-quantified at the anti-LTA antibody level by a passive haemagglutination test (PHA). ${ }^{13}$ Two-fold dilutions $(25 \mu \mathrm{l})$ of the anti-LTA serum were dispensed into the wells of U-bottomed, 96-well microtitration plates (Nunc), followed by $25 \mu \mathrm{l}$ of an SRBC suspension ( $2 \%$ in PBS, pH 7.2) sensitised with $E$. faecalis LTA (Sigma). The haemagglutinating titre of one representative rabbit immune serum was 1 in 5120 .

A mixture of equal amounts of the test specimen and a 1 in 320 dilution of the above rabbit antiserum was incubated for $2 \mathrm{~h}$ at $37^{\circ} \mathrm{C}$ and overnight at $4^{\circ} \mathrm{C}$. A supernate of the mixture was incubated with an equal volume of a $2 \%$ suspension of SRBC sensitised with LTA for $3 \mathrm{~h}$ at room temperature, to determine the haemagglutination inhibition effects of the test specimens. The minimum inhibitory doses of reference strain $E$. hirae LTA-2 (diacyl-[phosphatidylkojibiosyl] glycerol) and a polyglycerophosphate ${ }^{14}$ (a gift from Dr K. Kato) were 20 and $500 \mu \mathrm{g} / \mathrm{ml}$, respectively. The LTA content of the test specimens, with and without LTA, was graded semi-quantitatively into complete $(++)$, partial $(+)$ and no inhibition $(-)$.

\section{Glucan production}

Test strains were cultured in Brain-Heart Infusion Broth (Nissui Corp.) at $37^{\circ} \mathrm{C}$ for $18 \mathrm{~h}$, and one drop of the growth was inoculated into $4 \mathrm{ml}$ of Tryptic Soy Broth (Difco) supplemented with sucrose 5\%. ${ }^{15}$ After incubation for $48 \mathrm{~h}$ at $37^{\circ} \mathrm{C}$, the supernate was separated by centrifugation at $1500 \mathrm{~g}$ for $20 \mathrm{~min}$ and mixed with an equal volume of absolute ethanol. The resulting turbidity and precipitation due to soluble glucan in the culture supernate were compared with the non-inoculated control medium which was similarly treated. Glucan production was expressed as either positive $(+)$ or negative $(-)$.
Antibiotic susceptibility of test and reference viridans streptococci

Disks (Tridisk ${ }^{\mathrm{R}}$, Eiken Kagaku Co. Ltd, Tokyo) containing various antimicrobial agents were applied to the surface of Mueller-Hinton S Disk Agar (Eiken Kagaku Co. Ltd) plates which were inoculated with $0 \cdot 1 \mathrm{ml}$ of a culture containing $c \cdot 10^{8} \mathrm{cfu} / \mathrm{ml}$ from KD patients or control subjects and of reference type strains. After incubation for $20 \mathrm{~h}$ at $37^{\circ} \mathrm{C}$, the plates were examined for inhibition of growth around the disks, according to the manufacturer's instructions. When the inhibitory zone was $>1 \mathrm{~mm}$, the streptococci were taken to be sensitive. Antibiotics tested were : cephalexin $(5,10$ and $30 \mu \mathrm{g} /$ disk $)$, cefaclor (5, 10 and $30 \mu \mathrm{g}$ ), ampicillin $(2,5$ and $20 \mu \mathrm{g}$ ); amoxicillin (2, 5 and $20 \mu \mathrm{g})$; minocycline (2, 5 and $30 \mu \mathrm{g})$; and erythromycin $(0 \cdot 5,2$ and $10 \mu \mathrm{g})$.

\section{Results}

\section{Bacterial isolates from KD patients and control children}

Table I shows that gram-positive, catalase-negative cocci (tentatively classified as Streptococcus spp.,

Table III. Re-evaluation of $S$. sanguis II and $S$. mitis identified with API Strep 20 kit by relative DNA homology values with DNA of type strains*

\begin{tabular}{|c|c|c|c|}
\hline \multicolumn{2}{|l|}{ API Strep 20 kit } & \multicolumn{2}{|c|}{ DNA-DNA hybridisation $\dagger$} \\
\hline $\begin{array}{l}\text { Strain } \\
\text { and source }\end{array}$ & $\begin{array}{l}\text { Number of } \\
\text { strains }(\%)\end{array}$ & $\begin{array}{l}\text { Strain } \\
\text { and source }\end{array}$ & $\begin{array}{l}\text { Number of } \\
\text { strains }(\%)\end{array}$ \\
\hline \multirow{2}{*}{$\begin{array}{l}\text { KD: } \\
\quad \text { S. sanguis II } \ddagger\end{array}$} & & & \\
\hline & $18(100)$ & $\begin{array}{l}\text { S. oralis } \\
\text { S. mitis } \\
\text { S. parasanguis } \\
\text { S. sanguis } \\
\text { Unknown strains }\end{array}$ & $\begin{array}{l}8(44 \cdot 4) \\
3(37 \cdot 5) \\
1(5 \cdot 5) \\
1(5 \cdot 5) \\
5(27 \cdot 7)\end{array}$ \\
\hline \multirow{2}{*}{$\begin{array}{l}\text { Control: } \\
\quad \text { S. sanguis II }\end{array}$} & & & \\
\hline & $9(100)$ & $\begin{array}{l}S . \text { oralis } \\
S . \text { mitis } \\
S . \text { sanguis } \\
\text { Unknown strains }\end{array}$ & $\begin{array}{l}4(44 \cdot 4) \\
1(11 \cdot 1) \\
1(11 \cdot 1) \\
3(33 \cdot 3)\end{array}$ \\
\hline \multicolumn{4}{|l|}{ KD: } \\
\hline S. mitis & $34(100)$ & $\begin{array}{l}\text { S. oralis } \\
\text { S. mitis } \\
\text { S. parasanguis } \\
\text { S. sanguis } \\
\text { Unknown strains }\end{array}$ & $\begin{array}{c}5(14 \cdot 7) \\
9(26.4) \\
3(8 \cdot 8) \\
1(2 \cdot 9) \\
16(47 \cdot 0)\end{array}$ \\
\hline \multicolumn{4}{|l|}{ Control } \\
\hline S. mitis & $7(100)$ & $\begin{array}{l}\text { S. oralis } \\
\text { S. mitis } \\
\text { Unknown strains }\end{array}$ & $\begin{array}{l}0(0) \\
4(57 \cdot 1) \\
3(42 \cdot 0)\end{array}$ \\
\hline
\end{tabular}

* S. dysgalactiae NCFB 2023, S. suis NTCC 10232, S. pneumoniae NCTC 7465, $S$. oralis NCTC 11427, S. mitis NCTC 12261 (neotype), $S$. sanguis ATCC 10556, S. parasanguis ATCC 15912, S. gordonii NCTC $7865, S$. salivarius ATCC 7072 and S. intermedius ATCC 27335.

$\uparrow$ See Materials and methods.

$\ddagger$ Strains of $S$. sanguis II or $S$. pneumoniae were included in $S$. sanguis II.

$\S$ Strains not identified by homology with DNA of the above type strains. 
Table IV. The biological activities of extracellular products of viridans streptococci $(52 \mathrm{KD}, 16$ control, three reference and four type strains)

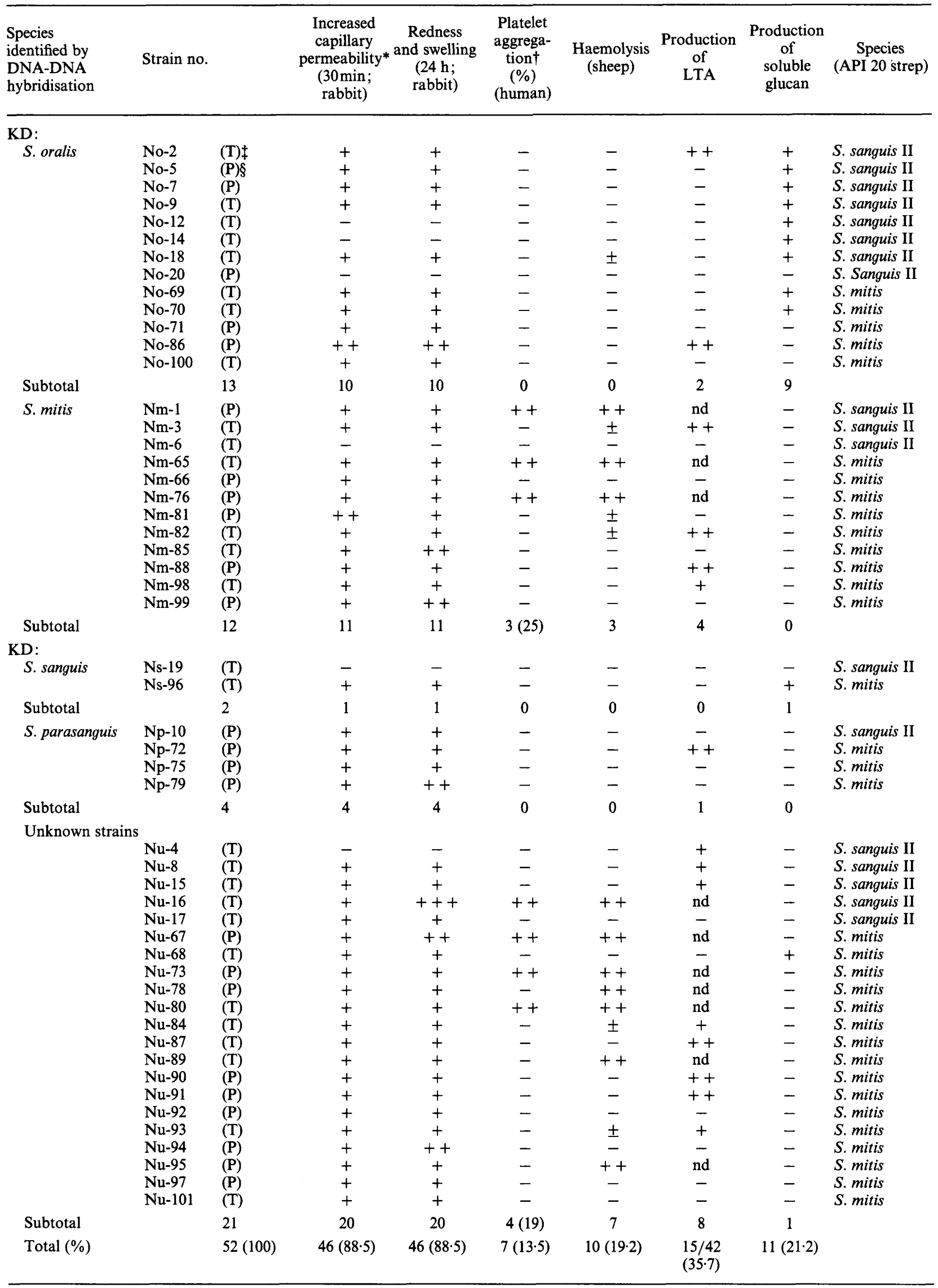


Table IV continued

\begin{tabular}{|c|c|c|c|c|c|c|c|c|c|}
\hline \multirow[t]{2}{*}{$\begin{array}{l}\text { Species } \\
\text { identified by } \\
\text { DNA-DNA } \\
\text { hybridisation }\end{array}$} & \multicolumn{2}{|c|}{ Strain no. } & \multirow[t]{2}{*}{$\begin{array}{c}\text { Increased } \\
\text { capillary } \\
\text { permeability* } \\
\text { (30min; } \\
\text { rabbit) }\end{array}$} & \multirow[t]{2}{*}{$\begin{array}{l}\text { Redness } \\
\text { and swelling } \\
\text { ( } 24 \mathrm{~h} ; \\
\text { rabbit) }\end{array}$} & \multirow[t]{2}{*}{$\begin{array}{l}\text { Platelet } \\
\text { aggrega- } \\
\text { tion } \dagger \\
(\%) \\
\text { (human) }\end{array}$} & \multirow[t]{2}{*}{$\begin{array}{l}\text { Haemolysis } \\
\text { (sheep) }\end{array}$} & \multirow[t]{2}{*}{$\begin{array}{c}\text { Production } \\
\text { of } \\
\text { LTA }\end{array}$} & \multirow[t]{2}{*}{$\begin{array}{c}\text { Production } \\
\text { of } \\
\text { soluble } \\
\text { glucan }\end{array}$} & \multirow[t]{2}{*}{$\begin{array}{c}\text { Species } \\
\text { (API 20'strep) }\end{array}$} \\
\hline & & & & & & & & & \\
\hline S. oralis & No-21 & (T) & + & + & - & - & ++ & - & S. sanguis II \\
\hline & No-22 & (P) & + & + & - & - & $+t$ & - & S. sanguis II \\
\hline & No-23 & (T) & + & + & - & - & - & - & $S$. sanguis II \\
\hline & No-27 & (T) & + & + & - & - & - & + & S. sanguis II \\
\hline Subtotal & & 4 & 4 & 4 & 0 & 0 & 2 & 1 & \\
\hline S. mitis & $\mathrm{Nm}-28$ & (P) & + & + & - & - & ++ & - & S. sanguis II \\
\hline & $\mathrm{Nm}-103$ & (P) & + & + & + & - & - & - & S. mitis \\
\hline & Nm-105 & (T) & + & ++ & - & - & - & - & S. mitis \\
\hline & Nm-108 & (T) & ++ & $++t$ & + & ++ & nd & - & S. mitis \\
\hline & Nm-109 & (T) & + & ++ & - & - & - & - & S. mitis \\
\hline Subtotal & & 5 & 5 & 5 & $2(40)$ & 1 & 1 & 0 & \\
\hline S. sanguis & Ns-25 & $(\mathrm{T})$ & + & + & - & - & - & - & S. sanguis II \\
\hline Subtotal & & 1 & 1 & 1 & 0 & 0 & 0 & 0 & \\
\hline \multicolumn{10}{|c|}{ Unknown strains } \\
\hline & $\mathrm{Nu}-24$ & $(\mathrm{~T})$ & ++ & +++ & ++ & ++ & nd & - & S. sanguis II \\
\hline & $\mathrm{Nu}-26$ & (P) & + & + & - & ++ & nd & - & S. sanguis II \\
\hline & $\mathrm{Nu}-29$ & (T) & + & + & - & - & - & + & S. sanguis II \\
\hline & $\mathrm{Nu}-104$ & (T) & + & ++ & - & - & - & - & S. mitis \\
\hline & $\mathrm{Nu}-107$ & (T) & + & $+t$ & - & - & + & - & $S$. mitis \\
\hline & $\mathrm{Nu}-110$ & (P) & + & ++ & ++ & ++ & nd & - & S. mitis \\
\hline Subtotal & & 6 & 6 & 6 & $2(33)$ & 3 & 1 & 1 & \\
\hline Total & & $16(100)$ & $16(100)$ & $16(100)$ & $4(25 \cdot 0)$ & $4(25 \cdot 0)$ & $\begin{array}{c}4 / 12 \\
(33 \cdot 6)\end{array}$ & $2(12 \cdot 5)$ & \\
\hline \multicolumn{10}{|c|}{ Reference strains } \\
\hline S. parasang & mitis AT & (C 903) & + & + & - & - & + & - & \\
\hline$S$. oralis $(S$ & ATCC 15 & 11) & + & + & - & - & + & - & \\
\hline$S$. oralis ( $S$ & is ATCC98 & & + & + & - & - & - & + & \\
\hline \multicolumn{10}{|l|}{ Type strains } \\
\hline S. oralis $(\mathrm{N}$ & 11427) & & + & + & - & - & - & - & \\
\hline S. mitis (N) & 12261 , neo & pe) & + & + & - & - & + & - & \\
\hline S. sanguis ( & C 10556) & & + & - & - & - & - & + & \\
\hline S. gordonii & (C 7865) & & + & - & - & - & - & + & \\
\hline Total & & $7(100)$ & $7(100)$ & $4(57)$ & 0 & 0 & $3(43)$ & $3(43)$ & \\
\hline
\end{tabular}

nd, haemolysis of LTA-sensitised sheep erythrocytes could not be used to determine LTA production

* Leakage of Evans blue.

$\dagger$ Scored by $\mathrm{OD}_{660}$ reduction $(\%):-<10 \%,+10-50 \%,++>50 \%$.

$\ddagger$ Isolated from tooth surface.

$\S$ Isolated from pharynx.

Enterococcus spp. and Lactococcus spp.) accounted for 61 and $55 \%$ of all bacterial strains (256 and 85 isolates) from the tooth surface and throat swabs of 89 $\mathrm{KD}$ patients and 23 controls.

\section{Identification of gram-positive, catalase-negative cocci}

Ninety-eight strains of gram-positive, catalasenegative cocci isolated from $22 \mathrm{KD}$ patients and 27 strains from 11 control children were identified according to their biochemical activities with an API Strep 20 kit (table II); $18 \%$ of strains from KD patients and $33 \%$ of those from control individuals were assigned to $S$. sanguis II (including $S$. sanguis II or $S$. pneumoniae group) and 35 and $26 \%$ of the isolates from KD and control children were identified as $S$. mitis, respectively. (Hereafter these streptococci will be collectively referred to as viridans streptococci.) The remainder belonged to miscellaneous species (table II).
Identification of viridans streptococci by DNA-DNA hybridisation

Strains biochemically classified as $S$. sanguis II and $S$. mitis were further identified by fluorometric DNADNA hybridisation (table III). Nearly half (12 of 27 strains) of the $S$. sanguis II group, irrespective of source, were identified as $S$. oralis, and then $S$. mitis, $S$. sanguis and $S$. parasanguis, in that order. One-third of biochemical $S$. sanguis II strains were unidentifiable. The predominant species (13 of 41 strains) in the biochemical $S$. mitis group was identified genetically as $S$. mitis, followed by $S$. oralis, but nearly half the biochemical $S$. mitis strains could not be identified genetically. Thus, $13(25 \%)$ and $12(23 \%)$ strains of 52 isolates from KD patients were identified as $S$. oralis and $S$. mitis, respectively. Among those from the control children, four $(25 \%)$ and five $(31 \%)$ of 16 were $S$. oralis and $S$. mitis, respectively. Viridans 


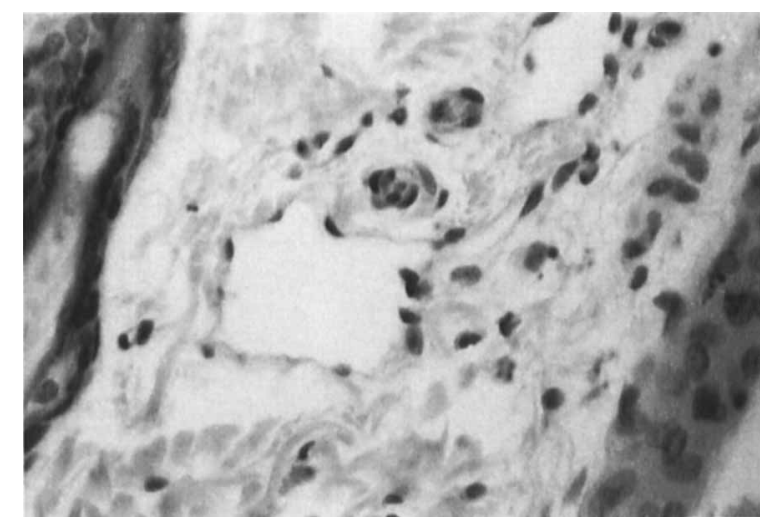

Fig. 1. Histopathological changes in rabbit skin 30 min after intradermal injection of a culture supernate concentrate of $S$. mitis strain Nm-65. H and E stain; $\times 280$.

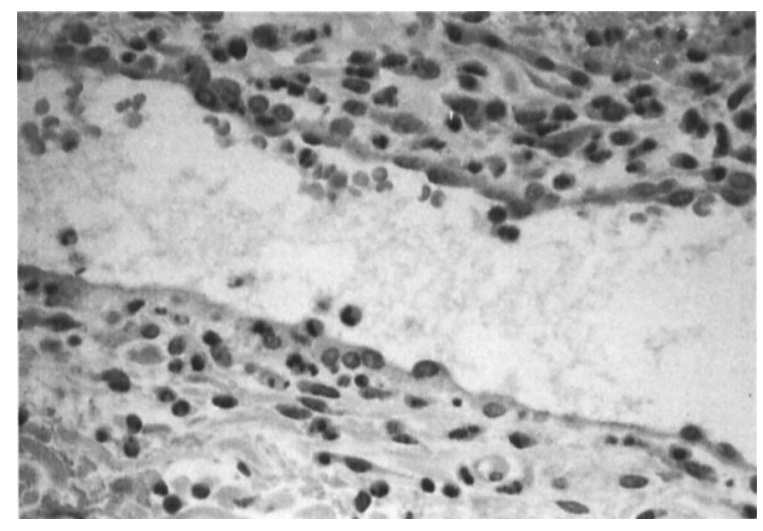

Fig. 2. Histopathological changes in rabbit skin $24 \mathrm{~h}$ after intradermal injection of a culture supernate concentrate of $S$. oralis strain No-23. H and E stain; $\times 280$.

streptococci used as reference strains, namely $S$. mitis ATCC903, S. mitis ATCC6249 and $S$. mitis ATCC15911 were identified as $S$. parasanguis, $S$. oralis and $S$. parasanguis, respectively, and both $S$. oralis ATCC9811 and S. parasanguis ATCC15909 were identified as $S$. oralis.

\section{Biological activities of extracellular products of isolates of viridans streptococci from KD patients and control children}

Induction of increased capillary permeability and vasculitis in rabbit skin. As shown in table IV, culture supernate concentrates of $88 \%$ of KD strains caused increased capillary permeability without bleeding for between $5 \mathrm{~min}$ and $3 \mathrm{~h}$ after intradermal injection. The culture supernate concentrates of all 16 strains from control subjects and those of seven reference strains also caused an increase in capillary permeability. The enhanced capillary permeability in the rabbit skin by test and reference viridans streptococci was followed by redness, swelling and sometimes bleeding after a few hours and up to $48 \mathrm{~h}$; this lasted for 4 days in some animals. The two type strains, $S$. sanguis ATCC10556
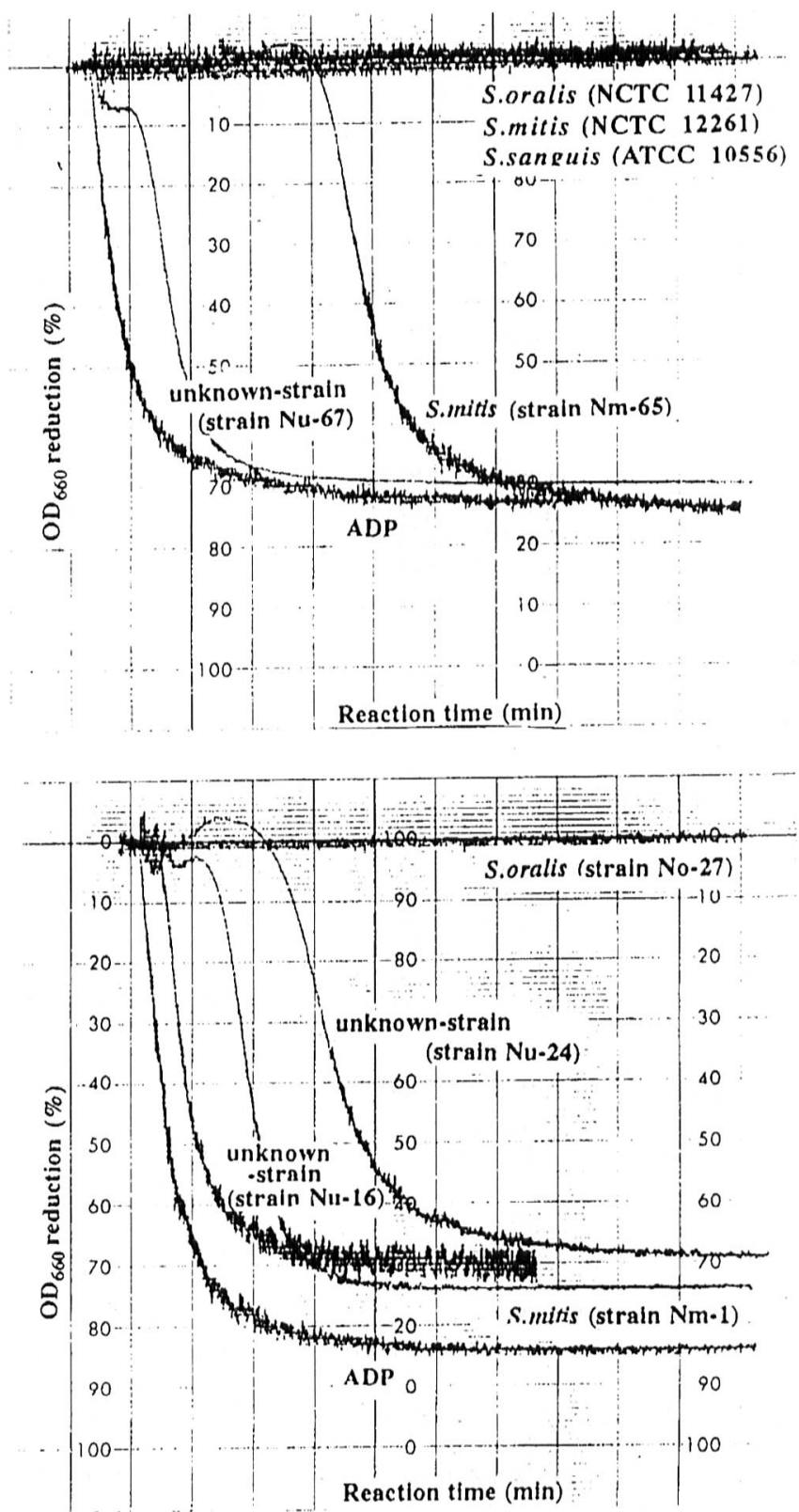

Fig. 3. Aggregation of human blood platelets by a culture supernate concentrate of viridans streptococci, fresh clinical isolates and type strains. Aggregation of a reaction mixture consisting of $200 \mu \mathrm{l}$ of PRP and $20 \mu$ l (containing $20 \mu g$ of protein) of a test specimen was determined with an aggregometer; $10^{-3} \mathrm{M}$ ADP was the reference aggregation agent.

and S. gordonii NCTC7865, did not produce these signs.

Histological examination of the test skin sites showing the early reaction revealed increased dilatation of the veins and capillaries in the dermis, but no infiltration of inflammatory cells (fig. 1). The lesions in the later stages of the reaction were characterised by extravasation of many neutrophils along dilated veins, where the endothelial cells appeared to be hypertrophic. Perivascular fibroblasts increased in number and their cytoplasm was hypertrophic (fig. 2). Massive infiltration of neutrophils occasionally resulted in foci of abscess-like changes (not shown).

Human blood platelet aggregation and SRBC haemolysis. Table IV shows that $(25 \%)$ three of 12 S. mitis 
Table V. Comparison of drug susceptibility among viridans group streptococci isolated from KD patients and control children with those of reference and type strains

\begin{tabular}{|c|c|c|c|c|c|c|c|c|c|c|c|c|c|c|c|c|c|c|c|}
\hline \multirow{3}{*}{ Strains } & \multirow{3}{*}{$\begin{array}{c}\text { Number } \\
\text { tested }\end{array}$} & \multicolumn{18}{|c|}{ Number of strains resistant to } \\
\hline & & \multicolumn{3}{|c|}{ CEX* } & \multicolumn{3}{|c|}{$\mathrm{CCL}$} & \multicolumn{3}{|c|}{ ABPC } & \multicolumn{3}{|c|}{ AMPC } & \multicolumn{3}{|c|}{ MINO } & \multicolumn{3}{|c|}{ EM } \\
\hline & & 30 & 10 & $5+$ & 30 & 10 & 5 & 20 & 5 & 2 & 20 & 5 & 2 & 30 & 5 & 2 & 10 & 2 & 0.5 \\
\hline \multicolumn{20}{|l|}{$\mathrm{KD}$} \\
\hline S. oralis & 13 & 7 & 7 & 12 & 5 & 8 & 9 & 0 & 0 & 5 & 0 & 0 & 1 & 0 & 5 & 8 & 5 & 6 & 9 \\
\hline S. mitis & 12 & 6 & 6 & 9 & 3 & 6 & 6 & 0 & 0 & 5 & 0 & 0 & 2 & 0 & 1 & 4 & 1 & 2 & 6 \\
\hline S. sanguis & 2 & 0 & 2 & 2 & 0 & 0 & 0 & 0 & 0 & 0 & 0 & 0 & 0 & 0 & 1 & 1 & 1 & 1 & 1 \\
\hline S. parasanguis & 4 & 2 & 2 & 2 & 0 & 2 & 2 & 0 & 0 & 0 & 0 & 0 & 1 & 0 & 1 & 2 & 0 & 1 & 2 \\
\hline Unknown strains & 21 & 10 & 13 & 15 & 6 & 9 & 10 & 0 & 1 & 7 & 0 & 0 & 4 & 0 & 2 & 11 & 8 & 9 & 12 \\
\hline \multicolumn{20}{|l|}{ Control: } \\
\hline S. oralis & 4 & 2 & 2 & 2 & 2 & 2 & 2 & 0 & 0 & 2 & 0 & 0 & 0 & 0 & 2 & 2 & 2 & 2 & 2 \\
\hline S. mitis & 5 & 3 & 3 & 3 & 2 & 3 & 3 & 0 & 1 & 2 & 0 & 0 & 2 & 0 & 1 & 1 & 4 & 4 & 4 \\
\hline S. sanguis & 1 & 1 & 1 & 1 & 0 & 0 & 1 & 0 & 0 & 0 & 0 & 0 & 0 & 0 & 1 & 1 & 1 & 1 & 1 \\
\hline Unknown strains & 6 & 3 & 4 & 5 & 2 & 3 & 3 & 0 & 1 & 2 & 0 & 1 & 2 & 0 & 1 & 4 & 2 & 2 & 3 \\
\hline \multicolumn{20}{|l|}{ Reference strains } \\
\hline $\begin{array}{l}\text { S. parasanguis } \\
\text { (S. mitis ATCC903) }\end{array}$ & & 0 & 0 & 0 & 0 & 0 & 0 & 0 & 0 & 0 & 0 & 0 & 0 & 0 & 0 & 0 & 0 & 0 & 0 \\
\hline $\begin{array}{l}\text { S. oralis } \\
\quad(S . \text { mitis ATCC15911) }\end{array}$ & & 0 & 0 & 0 & 0 & 0 & 0 & 0 & 0 & 0 & 0 & 0 & 0 & 0 & 0 & 0 & 0 & 0 & 0 \\
\hline $\begin{array}{l}\text { S. oralis } \\
\quad(S . \text { oralis ATCC } 9811)\end{array}$ & & 0 & 0 & 0 & 0 & 0 & 0 & 0 & 0 & 0 & 0 & 0 & 0 & 0 & 0 & 0 & 0 & 0 & 0 \\
\hline \multicolumn{20}{|l|}{ Type strains } \\
\hline S. oralis NCTC 11427 & & 0 & 0 & 0 & 0 & 0 & 0 & 0 & 0 & 0 & 0 & 0 & 0 & 0 & 0 & 0 & 0 & 0 & 0 \\
\hline S. mitis NCTC 12261 & & 0 & 0 & 0 & 0 & 0 & 0 & 0 & 0 & 0 & 0 & 0 & 0 & 0 & 0 & 0 & 0 & 0 & 0 \\
\hline S. sanguis ATCC 10556 & & 0 & 0 & 0 & 0 & 0 & 0 & 0 & 0 & 0 & 0 & 0 & 0 & 0 & 0 & 0 & 0 & 0 & 0 \\
\hline S. gordonii NCTC 7865 & & 0 & 0 & 0 & 0 & 0 & 0 & 0 & 0 & 0 & 0 & 0 & 0 & 0 & 0 & 0 & 0 & 0 & 0 \\
\hline
\end{tabular}

* CEX, cephalexin; CCL, cefaclor; ABPC, ampicillin; AMPC, amoxycillin; MINO, minocycline; EM, erythromycin.

$\dagger$ Drug content ( $\mu$ g disk).

strains from KD and (40\%) two of five $S$. mitis strains from control aggregated YT blood platelets, whereas none of $17 \mathrm{~S}$. oralis strains from KD and control subjects caused significant aggregation (fig. 3). Culture supernate concentrates of seven test strains of $S$. sanguis and $S$. parasanguis were inactive in this assay, but six $(22 \%)$ of 27 strains whose species remained unknown, were powerfully active. Seven reference strains did not form extracellular products capable of causing platelet aggregation.

Table IV demonstrates a significant parallel between the ability of culture supernate concentrates to aggregate human blood platelets and to haemolyse SRBC although six of 27 concentrates of unidentified viridans streptococci strongly haemolysed SRBC but did not cause blood platelet aggregation.

Detection of LTA in the test specimens. Since LTA was detected by the PHA inhibition test with LTAsensitised SRBC, culture supernate concentrates showing haemolytic activity against SRBC could not be assayed for the presence of LTA. Within this limitation, LTA was detected in the culture supernate concentrates of four $S$. oralis, five $S$. mitis and nine unidentified strains among a total of $42 \mathrm{KD}$ and 12 control strains that showed no haemolysis, indicating that $35 \%$ of viridans streptococci tested produced extracellular LTA. LTA was detected in the culture supernates of $(43 \%)$ three of seven reference and type strains (table IV).

Glucan production. Production of extracellular, sol- uble glucan in the medium supplemented with sucrose was almost confined to $S$. oralis strains, $(69 \%)$ nine of $13 \mathrm{KD}$ strains and $(25 \%)$ one of four control strains. Only exceptional strains of viridans streptococci other than $S$. oralis produced extracellular glucan. Three of seven reference or type strains gave positive results in this test (table IV).

\section{Drug susceptibility of test viridans streptococci and type or reference viridans strains}

All 68 fresh isolates of viridans streptococci, irrespective of species or source, showed greater resistance to six test antimicrobial drugs compared with serially subcultured reference strains. This was particularly true with cephalosporins such as cephalexin and cefaclor with erythromycin. Acquisition of resistance to other drugs, particularly the broad-spectrum semi-synthetic $\beta$-lactam agents such as ampicillin and amoxycillin, was minimal (table V).

\section{Discussion}

This study showed that a major group of bacteria isolated from the oral cavity of KD patients and nonKD control children included $S$. sanguis II ( $S$. sanguis II or $S$. pneumoniae) and $S$. mitis, identified by biochemical tests, although the taxonomy of these viridans streptococci has not yet been finally estab- 
lished. ${ }^{16-18}$ Initially, we tried to identify the viridans streptococci by fluorometric DNA-DNA hybridisation, ${ }^{7}$ with 10 type strains as reference strains. When the homology value between the test and the type strain was $>70 \%$, a test strain was identified as being of the same species as the respective type strain. The isolates homologous with several type strains were unidentified. No KD-specific bacteria were identified by DNA hybridisation studies. The novel finding in the present study was that during growth many viridans streptococci released biologically active, extracellular products that were responsible for increased capillary permeability, erythrogenic activity, human blood platelet aggregation and SRBC haemolysis, as well as production of LTA and glucan. However, there were no significant differences in the isolation rates of the viridans streptococci producing biologically active extracellular products between $\mathrm{KD}$ patients, agematched non-KD patients and healthy children.

The ability to aggregate human blood platelets was much more restricted to the culture supernate concentrates of a limited number of viridans streptococci than other effects such as changes in rabbit skin. However, there were no significant differences between $\mathrm{KD}$ and control isolates in the isolation rates of viridans streptococci whose culture supernates caused blood platelet aggregation. A preliminary study demonstrated that there are significant individual differences in the susceptibility of platelets to aggregation factor in the culture supernate amongst members of one $S$. mitis strain (strain Nm-65).

Human platelet aggregation and SRBC haemolytic activity correlated well. Nearly all the culture supernates that caused platelet aggregation haemolysed SRBC, although the reverse was not necessarily true. Nevertheless, our attempt to purify a platelet aggregation principle revealed that a fraction causing strong platelet aggregation activity was distinct from a concentrate that haemolysed SRBC, by DEAE column chromatography (unpublished data).

Studies on biologically active, extracellular products of viridans streptococci are limited, but there are several studies on viridans streptococci associated with subacute bacterial endocarditis (SBE). Proteases have been identified in culture supernate of $S$. mitis, $S$. sanguis, $S$. mutans, $S$. salivarius and S.MG intermedius isolated from confirmed cases of $\mathrm{SBE} ; \mathbf{1 9}^{\mathbf{2} 0}$ extracellular neuraminidase is produced by a $S$. sanguis strain associated with $\mathrm{SBE},{ }^{21}$ and an immunoglobulin Al degrading enzyme has been reported as an extracellular product of oral streptococci such as $S$. sanguis, $S$. mitis and $S$. oralis. ${ }^{22}$ The interaction between human platelets and $S$. sanguis whole cells was studied by Herzberg et al. ${ }^{23-25}$ to elucidate the pathological mechanisms in SBE. They observed that the interaction was mediated by two or more antigens in the fibrillar surface appendages and showed that one antigen designated as the class I component bound with the platelets, that the other antigen (class II component) triggered platelet aggregation and that the class II component shared a cross-reactive immunodeterminant with collagen. ${ }^{26,27}$ Consequently, the extracellular platelet aggregation factor reported here may be of bacterial cell-surface origin. However, a recent study showed that YT platelets thoroughly washed with ACD (citric acid- $0.8 \%$ w/v sodium citrate $-2 \cdot 2 \% \mathrm{w} / \mathrm{v}$ glucose $2 \cdot 2 \% \mathrm{w} / \mathrm{v}$ ), to remove blood plasma components, and resuspended in ACD-0.01 M PBS (pH 8.5) were aggregated by a test extracellular aggregation factor (unpublished data). As Sullam et $a l^{28}$ reported that plasma components were needed for platelet aggregation by whole $S$. sanguis and $S$. salivarius cells, the mechanism of platelet aggregation by the culture supernate concentrates described here may differ from that of whole bacterial cells.

Because of the reported immunobiological activity of $E$. faecalis ( $E$. hirae) $\mathrm{LTA}^{14}$ the distribution of extracellular LTA in viridans streptococci was examined. Extracellular LTA may be LTA which was originally associated with the cell walls before being released extracellularly in a manner similar to the extracellular glycoprotein antigen of some $S$. sanguis species. $^{29}$

Regarding the correlation between the human platelet aggregation and the presence of extracellular LTA, the fact that the LTA-containing culture supernates of a few test strains did not show any aggregation excludes the possibility that the platelet aggregation is due to extracellular LTA. Indeed, a report that the LTA of group A streptococci bound to human blood platelets but did not cause platelet aggregation, ${ }^{30}$ suggests the opposite. The extracellular LTA of some viridans streptococci bound to the platelets and may have interfered with platelet aggregation.

A recent study by Furusho et $a l .^{31}$ showed that an insoluble glucan produced by $S$. sanguis, particularly in the presence of detergent, stimulated interleukin- $1 \alpha$ production in human monocyte cultures, and prompted us to investigate the production of extracellular (soluble) glucan by viridans streptococci. Most genetically identified $S$. oralis but none of the $S$. mitis strains produced glucan extracellularly. No correlation was found between glucan production, platelet aggregation, haemolytic activity and the existence of LTA.

Viridans streptococci freshly isolated from $\mathrm{KD}$ patients and control children in general showed greater resistance to the antibiotics commonly prescribed for paediatric patients, especially to the cephalosporins and erythromycin, than the type culture strains.

We also demonstrated that erythrogenic culture supernates of two representative strains of $S$. oralis and $S$. mitis were capable of inducing serum tumour necrosis factor- $\alpha$ (TNF- $\alpha$ ), interleukin-6 (IL-6) and gamma interferon (INF- $\gamma$ ) by administration into appropriately primed mice (Takada et al., unpublished observations). The concentrate also induced TNF- $\alpha$, IL-6 and a thymocyte activating factor (TAF, essentially IL-1) in murine peritoneal macrophages and 
human monocyte cultures. Partially purified "toxin" fractions (F-1 and F-2) were obtained from the culture supernate of one S. mitis strain. The erythrogenic F-1 fraction induced high levels of serum TNF- $\alpha$, IL- 6 and IFN- $\gamma$ in mice, and stimulated human peripheral whole blood to produce the above cytokines. This fraction also induced TAF and IL-6 activity in human umbilical vascular endothelial cells (HUVEC) and gingival fibroblast cultures. On the other hand fraction F2 , which increases capillary permeability but is not erythogenic to rabbit skin, functions as a class II histocompatibility antigen-restricted T-cell stimulator to induce interleukin-2 (IL-2), as a super-antigen on human lymphoid cells (Fujikawa et al., unpublished observations). Furukawa $e t$ al. further showed that fraction F-1, but not F-2, caused increased expression of intercellular adhesion molecule-1 and endotheliumlymphocyte adhesion molecule-1 on HUVEC,

\section{References}

1. Yanagawa H. Epidemiology of Kawasaki disease in Japan. In: Shulman ST (ed) Proceedings of the Second International Kawasaki Disease Symposium. New York, Alan R. Liss, Inc. 1987: pp. 5-17.

2. Furukawa S, Matsubara T, Jujoh $\mathrm{K}$ et al. Peripheral blood monocyte/macrophage and serum tumor necrosis factor in Kawasaki disease. Clin Immunol Immunopathol 1988; 48 : 247-251.

3. Leung DYM, Cotran RS, Kurt-Jones E, Burns JC, Newburger JW, Pober JS. Endothelial cell activation and high interleukin-1 secretion in the pathogenesis of acute Kawasaki disease. Lancet 1989; 2: 1298-1302.

4. Furukawa S, Imai K, Matsubara T et al. Increased levels of circulating intercellular adhesion molecule 1 in Kawasaki disease. Arthritis Rheum 1992; 35: 672-677.

5. The Japan Kawasaki Disease Research Committee. Diagnostic guideline of Kawasaki disease (4th revised edition). 1984

6. Muller HE. ABTS perioxidase medium as a highly sensitive plate assay for detection of hydrogen peroxide production in bacteria. J Microbiol Methods 1984; 2: 101-102.

7. Ezaki T, Hashimoto Y, Takeuchi et al. Simple genetic method to identify viridans group streptococci by colorimetric dot hybridization and fluorometric hybridization in microdilution wells. J Clin Microbiol 1988; 26: 1708-1713.

8. Ezaki T, Hashimoto Y, Yabuuchi E. Fluorometric deoxyribonucleic acid-deoxyribonucleic acid hybridization in microdilution wells as an alternative to membrane filter hybridization in which radioisotopes are used to determine genetic relatedness among bacterial strains. Int $J$ Syst Bacteriol 1989; 39: 224-229.

9. Ezaki T, Hashimoto Y, Yamamoto $\mathrm{H}$ et al. Evaluation of the microplate hybridization method for rapid identification of Legionella species. Eur J Clin Microbiol Infect Dis 1990; 9: 213-217.

10. van de Rijn I, Kessler RE. Growth characteristics of group A streptococci in a new chemically defined medium. Infect Immun 1980; 27 : 444-448.

11. Lowry OH, Rosebrough NJ, Farr AL, Randall RJ. Protein measurement with the Folin phenol reagent. J Biol Chem 1951; 193: 265-275.

12. Ohkuni H, Kimura Y. Increased capillary permeability in guinea pigs and rats by peptidoglycan fraction extracted from group A streptococcal cell walls. Exp Cell Biol 1976; 44: 83-94.

13. Hamada S, Mizuno J, Kotani S. Serological properties of cellular and extracellular glycerol teichoic acid antigens of Streptococcus mutans. Microbios 1979; 25: 155-166.

14. Tsutsui O, Kokeguchi S, Matsumura T, Kato K. Relationship of the chemical structure and immunobiological activities of lipoteichoic acid from Streptococcus faecalis indicating vascular inflammation (unpublished observations).

These findings lead us to speculate that some oral viridans streptococci can reproduce many of the pathological and clinical features and laboratory findings of $\mathrm{KD}$ through production of immunobiologically active extracellular products. Nevertheless, the fact that there were no differences in the recovery rates of these viridans streptococci indicates the involvement of secondary factors in the production of clinical signs and symptoms of $\mathrm{KD}$, if viridans streptococci are designated as the primary causative agents. Studies on the elucidation of possible secondary factors are currently in progress.

We are grateful to Dr K. Kato, School of Dentistry, Okayama University, for providing $E$. hirae, $E$. hirae LTA-2 and polyglycerophosphate preparations used in this study. This study was supported in part by a grant from the Japan Heart Foundation.
(Enterococcus hirae) ATCC9790. FEMS Microbiol Immunol 1991; 76: 211-218.

15. Gibbons RJ, Banghart SB. Synthesis of extracellular dextran by cariogenic bacteria and its presence in human dental plaque. Arch Oral Biol 1967; 12: 11-23.

16. Schmidhuber S, Kilpper-Balz R, Schleifer KH. A taxonomic study of Streptococcus mitis, $S$. oralis, and $S$. sanguis. System Appl Microbiol 1987; 10: 74-77.

17. Coykendall AL. Rejection of the type strain of Streptococcus mitis (Andrewes and Horder 1906): request for an opinion. Int J System Bacteriol 1989; 39: 207-209.

18. Kilian M, Mikkelsen L, Henrichsen J. Taxonomic study of viridans streptococci: Description of Streptococcus gordonii sp. nov. and emended descriptions of Streptococcus sanguis (White and Niven 1946), Streptococcus oralis (Bridge and Sneath 1982), and Streptococcus mitis (Andrewes and Horder 1906). Int J System Bacteriol 1989; 39: 471-484.

19. Straus DC, Mattingly SJ, Milligan TW. Production of extracellular material by streptococci associated with subacute bacterial endocarditis. Infect Immun 1977; 17: 148-156.

20. Straus DC. Protease production by Streptococcus sanguis associated with subacute bacterial endocarditis. Infect Immun 1982; 38: 1037-1045.

21. Straus DC, Portnoy-Duran C. Neuraminidase production by Streptococcus sanguis strain associated with subacute bacterial endocarditis. Infect Immun 1983; 41: 507-515.

22. Reinholdt J, Tomana M, Mortensen SB, Kilian M. Molecular aspects of immunoglobulin A1 degradation by oral streptococci. Infect Immun 1990; 58: 1186-1194.

23. Herzberg MC, Brintzenhofe KL, Clawson CC. Aggregation of human platelets and adhesion of Streptococcus sanguis. Infect Immun 1983; 39: 1457-1469.

24. Herzberg MC, Brintzenhofe KL, Clawson CC. Cell-free released components of Streptococcus sanguis inhibit platelet aggregation. Infect Immun 1983; 42: 394-401.

25. Herzberg MC, MacFarlane GD, Delzer PR. Streptococcus sanguis interactions with human platelets. In: Mergenhagen SE, Rosan B (eds) Molecular basis of oral microbial adhesion. Washington, DC, American Society for Microbiology 1985: 53-60.

26. Erickson PR, Herzberg MC. A collagen-like immunodeterminant on the surface of Streptococcus sanguis induces platelet aggregation. $J$ Immunol 1987; 138: 3360-3366.

27. Erickson PR, Herzberg MC, Tierney G. Cross-reactive immunodeterminants on Streptococcus sanguis and collagen. J Biol Chem 1992; 267: 10018-10023.

28. Sullam PM, Valone FH, Mills J. Mechanisms of platelet aggregation by viridans group streptococci. Infect Immun 1989; 55: 1743-1750. 
29. Schöller M, Klein JP, Sommer P, Frank R. Common antigens of streptococcal and non-streptococcal oral bacteria: characterization of wall-associated protein and comparison with extracellular protein antigen. Infect Immun 1983; 40: 1186-1191.

30. Beachey EH, Chiang TS, Offek I, Kang AH. Interaction of lipoteichoic acid of group A streptococci with human platelets. Infect Immun 1977; 16: 649-654.

31. Furusho K, Sato K, Kajino Y et al. Proposition to etiological study of Kawasaki disease-significant role of glucan produced by Streptococcus sanguis. Prog Med 1991; 11: 75-78 (in Japanese). 